\title{
Beware of the "Medusa"
}

\author{
Hazim J. Safi, MD, FACS
}

See related article on pages 2951-5 in the December 2014 issue.

[Furies]: "Just let Medusa come; then we shall turn/him into stone,"...

—Dante Alighieri. Inferno, Canto IX, lines 52-53.

The 1990s ushered in the endovascular revolution. It started with the treatment of endovascular aneurysm repair and, subsequently, expanded to thoracic endovascular aneurysm repair. Surgeons have now expanded indications for treatment of the ascending arch and extensive aneurysm.

The article by Kent and colleagues ${ }^{1}$ is an interesting report of using a hybrid approach of open surgical and endovascular repair for aneurysms involving the ascending aorta, arch, descending aorta, and thoracoabdominal aorta. It is one of a few reports that emphasizes both the excision and the replacement of the ascending aorta as integral parts of this combined approach.

By excising the ascending aorta, the complications associated with leaving the diseased ascending aorta (ie, retrograde aortic dissection, false aneurysm, and aneurysmal formation) are prevented. The new device by Kent and colleagues, ${ }^{1}$ the Bavaria graft, is built to fit this particular need.

However, the results in this small series, in an institution known for its excellence regarding treatment of aortic pathology, is only average. The combined hospital and 40 -day mortality is $10 \%$. The stroke rate, at $5 \%$, is of concern, as is the disturbingly high rate of temporary paraplegia/paraparesis of $20 \%$.
In addition, the weakness of any endovascular treatment is the prevalence of endoleak in type I (15\%), type II ( $5 \%)$, and enfolding of the graft $(5 \%)$. Moreover, there are shortcomings of placing a graft or stent graft in the descending thoracic aorta, specifically in patients with aortic dissection or connective tissue disorder because of the tendency of the remaining aorta to expand.

Thus, these results should be compared with the published results of open surgical repair for the ascending aorta, arch, and descending thoracic and thoracoabdominal aortic aneurysms, which include the following rates for mortality $(8 \% ; 5 \%$ in those with normal glomerular filtration rate), stroke (3\%), and paraplegia/paraparesis ( $1 \%-5 \%$, depending on the extent).

Furthermore, the durability of open surgical repair is excellent. Also, in the combined approach, cardiopulmonary bypass and profound hypothermia in this series were used in 14 of 20 cases. The whole idea of this technique was not to use profound hypothermia and circulatory arrest because of all the complications associated with them. I believe this detracts from the attractiveness of the hybrid approach.

For us, the real question is, "Will this hybrid technique withstand the test of time versus the frozen elephant technique?" Because "hybrid" arises from the Greek term for "mongrel" or "monster," only time and experience with this Medusa will tell!

\section{Reference}

1. Kent WDT, Appoo JJ, Bavaria JE, Herget EJ, Moeller P, Pochettino A, Wong JK. Results of type II hybrid arch repair with zone 0 stent graft deployment for complex aortic arch pathology. J Thorac Cardiovasc Surg. 2014;148:2951-5.

From the Department of Cardiothoracic and Vascular Surgery, The University of Texas Medical School at Houston, Houston, Tex.

Disclosures: Author has nothing to disclose with regard to commercial support.

Received for publication Sept 29, 2014; accepted for publication Sept 29, 2014.

Address for reprints: Hazim J. Safi, MD, FACS, Department of Cardiothoracic and

Vascular Surgery, The University of Texas Medical School at Houston, 6400

Fannin St, Suite 2850, Houston, TX 77030 (E-mail: Hazim.J.Safi@uth.tmc.edu).

J Thorac Cardiovasc Surg 2015;149:964

0022-5223/\$0.00

Published by Elsevier Inc. on behalf of The American Association for Thoracic

Surgery

http://dx.doi.org/10.1016/j.jtcvs.2014.09.098 